\title{
Another British disease? A recent increase in the prevalence of psychiatric morbidity
}

\author{
Glyn Lewis, Greg Wilkinson
}

\begin{abstract}
Aims and objective-To examine trends in the prevalence of psychiatric morbidity in Britain between 1977 and 1985 .

Design-Secondary analysis of two cross sectional population based surveys.

Setting-The first survey was conducted in 1977 in West London and the second in 1984-85 throughout Great Britain.

Participants-Members of the public randomly selected from the electoral register.

Measurements and main results-The main outcome was the prevalence of psychiatric morbidity assessed using the General Health Questionnaire, a self administered measure of neurotic symptoms.

There was an increase of at least $8 \%(95 \%$ confidence interval $6 \cdot 6,9 \cdot 8)$ in the prevalence of psychiatric morbidity between the times of the two surveys and this difference persisted after adjustment for any changes in the sex, age, employment status, marital status, social class, and housing tenancy between the two samples. When the analysis was restricted to the Greater London respondents of the Health and Lifestyle Survey a larger increase in psychiatric morbidity was seen. Conclusions-It is likely that there was an increase in the prevalence of psychiatric morbidity in Great Britain between these two surveys. Psychiatric morbidity is a public health problem of some importance and the causes of this increase require further study.
\end{abstract}

f Epidemiol Community Health 1993; 47: 358-361

There have been recent reports that the incidence of schizophrenia in Britain has been declining. ${ }^{12}$ Of more importance to public health, however, are the minor or neurotic psychiatric disorders, mostly depression and anxiety. Though these conditions, which will be called psychiatric morbidity, are less disabling than schizophrenia for an individual, they are more common and probably lead to a greater burden of disability for the community as a whole. ${ }^{34}$ Psychiatric morbidity is also associated with an increased likelihood of consulting a general practitioner. ${ }^{5}$

There have been suggestions that depression is increasing in the USA, particularly in younger people. ${ }^{67}$ Much of this evidence, however, is based on retrospective accounts of previous depressive episodes and is therefore likely to be subject to recall bias as older people are less likely to recall depressive episodes earlier in life. Nor will examining treated rates of depression give an accurate estimate of the population incidence or prevalence, as few subjects with psychiatric morbidity reach specialist psychiatric services for treatment. $^{8}$

The most accurate method of determining whether the prevalence of psychiatric morbidity is changing is to conduct two or more cross sectional community surveys, in the same geographical area, and using the same assessment of psychiatric morbidity but separated by an interval of several years. Such repeated surveys are relatively uncommon. ${ }^{9}$ Hagnell et $a l^{10}$ repeated a community survey conducted in the 1950 s after a delay of 20 years and found that the incidence of depression had doubled during the interval. The researchers used clinical assessments and diagnoses, however, rather than the more standardised assessments that are now available. Murphy et $a l^{11}$ used the Health Opinion Survey, a self administered questionnaire in two surveys (1952 and 1970) in Stirling County and did not find an increase in reported morbidity. A survey on a population based sample of the whole USA, using a similar assessment, found an increase in prevalence between 1957 and 1976, however, especially in men. ${ }^{12}$

There is, of course, no reason to suppose that trends in the prevalence of psychiatric morbidity will be similar over different time periods or in different places. We are not aware of any investigation of this issue in Great Britain. In Great Britain two large population based surveys were conducted in 1977 and 1985 using the same standardised assessment of psychiatric morbidity, the General Health Questionnaire (GHQ). ${ }^{13} 14$ This period was later than the one (1950-75) investigated in the studies mentioned above. The first of these surveys was carried out in West London, the West London Survey, ${ }^{15}$ and the second, the Health and Lifestyle Survey, ${ }^{16}$ used a sample from the whole of Great Britain. This provided an opportunity to examine the possibility that the prevalence of psychiatric morbidity in Britain has changed over recent years.

\section{Method}

The West London Survey was conducted in 1977 and details of the method have already been described. ${ }^{15}$ The sample consisted of 8502 people randomly selected from the electoral register. The sample was stratified into two bands according to the proximity to Heathrow Airport. Subjects completed the 30 item GHQ during an interview and in the presence of the interviewer. The area selected for the survey was bounded on the west by the boundary of Greater London and included the following boroughs: Brent; Camden, Hammersmith; Kensington and Chelsea; Lamb- 
eth; Kingston upon Thames (part); Merton; Wandsworth; Westminster; Richmond; Hounslow; Ealing and Hillingdon. The area therefore covered most of the western half of Greater London and was estimated to include 2342720 adults.

The Health and Lifestyle Survey collected data between autumn 1984 and July 1985 and details of the method have been given elsewhere. ${ }^{16}$ The electoral register was used to select a random sample of 12254 people in England, Wales, and Scotland, of whom 9003 (73.5\%) were interviewed. Information was collected at two home visits and on the second visit, the respondents were given the 30 item GHQ and asked to complete it in their own time and return it by post to the survey organisation.

The West London Survey used the 1972 version of the GHQ-30 while the Health and Lifestyle Survey used the 1978 version, in which the items are in a different order. To avoid confusion all the item numbers in this paper refer to the 1978 version. Two items in the 1972 version, items 7 ("been feeling on the whole you were doing things well") and 15 ("felt that you couldn't overcome your difficulties") are very slightly different from those of the 1978 version ("felt on the whole you were doing things well" and "felt you couldn't overcome your difficulties").

Those scoring 5 or more on the GHQ were classified as cases of psychiatric morbidity as this corresponds to the point at which a physician becomes concerned with someone's mental health. ${ }^{14}$ The GHQ was designed to include questions asking about negative aspects of mental health (for example, have you recently felt that life is entirely hopeless?) and positive aspects of mental health (for example, have you recently been feeling hopeful about your own future?). For some analyses the GHQ results are presented as the negative and positive scale scores. ${ }^{17}$ The GHQ negative scale was constructed by summing the "more than usual" items, as these are symptoms and therefore assess negative aspects of mental health. The negative items of the GHQ-30 are: 2 , $3,14,15,16,18,19,21,22,23,24,25,28,29,30$. The remainder were classified as positive items. The GHQ positive and negative scales were scored in the likert manner ${ }^{13}$ as this is more appropriate when treating the scores as continuous variables.

Rose $^{18}$ has argued that most medical illnesses are best considered as continua, and this argument can also be applied to psychiatric morbidity. It was decided to present results as "cases" of psychiatric morbidity as there is no reason to expect that using psychiatric morbidity as a continuous variable would lead to different results. ${ }^{19}$

Table I Characteristics of the samples: means and proportions (95\% CI)

\begin{tabular}{lllc}
\hline & $\begin{array}{l}\text { West London } \\
\text { Survey }\end{array}$ & $\begin{array}{l}\text { Health and } \\
\text { Lifestyle Survey }\end{array}$ & $\begin{array}{l}\text { p value } \\
\text { for } \\
\text { difference }\end{array}$ \\
\hline Sample size & 5684 & 6437 & \\
Date of survey & 1977 & $1984 / 1985$ & \\
Response rate (\%) & $66 \cdot 9$ & $52 \cdot 5$ & \\
Mean age & $46 \cdot 0(45 \cdot 5,46 \cdot 5)$ & $45.9(45 \cdot 5,46 \cdot 2)$ & $0 \cdot 53$ \\
Female (\%) & $56 \cdot 2(54 \cdot 9,57 \cdot 5)$ & $56 \cdot 6(55 \cdot 4,57 \cdot 8)$ & $0 \cdot 58$ \\
Divorced, widowed, or separated (\%) & $13 \cdot 9(13 \cdot 0,14 \cdot 8)$ & $14 \cdot 6(13 \cdot 7,15 \cdot 5)$ & $0 \cdot 24$ \\
In manual occupations (\%) & $50 \cdot 4(49 \cdot 1,51 \cdot 7)$ & $57 \cdot 7(56 \cdot 5,58 \cdot 9)$ & $<0 \cdot 0001$ \\
Unemployed (\%) & $1 \cdot 8(1.4,2 \cdot 2)$ & $5 \cdot 0(4 \cdot 5,5 \cdot 5)$ & $<0 \cdot 0001$ \\
Owning or buying own home (\%) & $53 \cdot 3(52 \cdot 0,54 \cdot 6)$ & $64 \cdot 1(62 \cdot 9,65 \cdot 3)$ & $<0 \cdot 0001$ \\
\hline
\end{tabular}

A few demographic variables were asked about in identical questions in both surveys. In addition to the sex and age of respondents, marital status, housing tenancy, and employment could therefore be compared between the two surveys. Subjects were classified as unemployed if they reported being without paid employment and were actively seeking work. The Registrar General's classification of social class was divided into manual and non-manual categories to compare the 1971 classification used in the West London Survey with the 1981 classification used in the Health and Lifestyle Survey.

Odds ratios with Cornfield confidence intervals and tests for heterogeneity were calculated using the program EGRET. ${ }^{20}$ The odds ratios were adjusted using logistic regression performed with the same program. The mean differences between the samples were adjusted using multiple regression with the GLM procedure of SAS. ${ }^{21}$

\section{Results}

Complete data were available on $66.9 \%$ of the West London Survey and $52.5 \%$ of the Health and Lifestyle Survey, $71.5 \%$ of the interviewed sample (table I). Those variables that could be compared between the samples are shown in table I. A larger proportion of respondents in the Health and Lifestyle Survey were unemployed and actively seeking work and owned or were buying their own home. A larger proportion of people were in manual occupations in the Health and Lifestyle Survey than in the West London Survey but this is because a smaller proportion of people are in manual occupations in London than in other parts of the country. In the London sample of the Health and Lifestyle Survey, $48 \%$ (95\% CI 44.8, $51 \cdot 2$ ) of the sample were in manual occupations.

Table II The prevalence (95\% CI) of psychiatric morbidity and odds ratios $(95 \%$ CI) before and after adjustment

\begin{tabular}{lcc}
\hline & $\begin{array}{c}\text { West London } \\
\text { Survey }\end{array}$ & $\begin{array}{l}\text { Health and } \\
\text { Lifestyle Survey }\end{array}$ \\
\hline Percentage cases of & & \\
psychiatric morbidity & $22 \cdot 4(21 \cdot 3,23 \cdot 5)$ & $31 \cdot 2(30 \cdot 1,32 \cdot 3)$ \\
Odds ratio & $1.00^{\star}$ & $1 \cdot 6(1 \cdot 5,1 \cdot 7)$ \\
Adjusted† Odds ratio & $1 \cdot 00^{\star}$ & $1 \cdot 6(1 \cdot 4,1 \cdot 7)$ \\
\hline * Baseline; + adjusted for age, sex, marital status, employment,
\end{tabular}

* Baseline; + adjusted for age, sex, marital status, employment, social class, and housing ownership.

There was a higher prevalence of psychiatric morbidity in the Health and Lifestyle Survey $(31.2 \%)$ than in the West London Survey $(22.4 \%$; table II). There was therefore an increase in the prevalence of psychiatric morbidity of $8.8 \%(95 \%$ CI $8.3,9.3)$. The prevalence of psychiatric morbidity in Greater London in the Health and Lifestyle Survey was $35 \cdot 1 \%(95 \%$ CI $31 \cdot 4,38 \cdot 8)$. The difference in prevalence between Greater London and the remainder of Britain is discussed in more detail elsewhere. ${ }^{22}$ When the Health and Lifestyle Survey and the West London Survey are compared the odds ratio for psychiatric morbidity was $1.6(95 \% \mathrm{CI} 1.5,1.7)$ and this estimate was unchanged after adjustment for the demographic variables (table II). 
All ages showed an increase in prevalence in the Health and Lifestyle Survey (table III) but this increase was lower in the 25-44 year age group (table III; heterogeneity test, $\mathrm{p}=0.01$ ). There was no evidence for any differential increase in psychiatric morbidity in the two sexes (heterogeneity test, $\mathrm{p}=0 \cdot 89$ ).

The increase in scores on the GHQ were mostly due to an increase in the GHQ negative scale. There was a smaller increase in scores on the GHQ positive scale (table IV). Adjusting the mean difference between the two samples for the effect of the sociodemographic variables did not change the estimates (table IV).

\section{Discussion}

The results of the two surveys suggest that there was an increase in the prevalence of psychiatric morbidity of at least $8 \%$ in Greater London between 1977 and 1985 after adjustment for a number of demographic variables. The earlier survey was conducted only in West London but the Health and Lifestyle Survey collected data on a sample from the whole of Great Britain. Though no data were available from 1977 on respondents in the remainder of Great Britain, it is likely that the whole of Great Britain also showed an increase in the prevalence of psychiatric morbidity during this period.

Earlier reports based upon retrospective accounts of previous illness have suggested that the younger age groups had higher rates of depression. ${ }^{6}$ The data presented here do not show a similar pattern, and the increase in the prevalence of psychiatric morbidity seemed to be greater in the older age groups. The difference in these results could reflect the different localities of the studies, but may result from the fact that retrospective accounts of previous episodes of depression are prone to recall bias. ${ }^{23}$

The response rate in the West London Survey was larger than that in the Health and Lifestyle Survey, though both surveys had a low response. There is some evidence that those with psychiatric morbidity are less likely to respond to surveys. ${ }^{24} 25$ This possible source of bias would therefore tend to increase the size of the difference in prevalence between the two surveys.

Two of the questions in the 1972 and 1978 versions of the GHQ were worded somewhat differently. In the West London Survey subjects

Table III Percentage cases (95\% CI) and odds ratios (95\% CI) for psychiatric morbidity by age group in the two samples

\begin{tabular}{|c|c|c|c|c|c|}
\hline \multirow[b]{2}{*}{ Age (y) } & \multicolumn{2}{|c|}{ West London Survey } & \multicolumn{2}{|c|}{ Health and Lifestyle Survey } & \multirow{2}{*}{$\begin{array}{l}\text { Odds ratios } \\
\text { baseline West } \\
\text { London Survey } \\
(95 \% \text { CI) }\end{array}$} \\
\hline & $\begin{array}{l}\text { Sample } \\
\text { size }\end{array}$ & $\begin{array}{l}\text { Percentage cases } \\
(95 \% \text { CI })\end{array}$ & $\begin{array}{l}\text { Sample } \\
\text { size }\end{array}$ & $\begin{array}{l}\text { Percentage cases } \\
(95 \% \text { CI })\end{array}$ & \\
\hline $\begin{array}{l}18-24 \\
25-44 \\
45-64 \\
65 \text { or over }\end{array}$ & $\begin{array}{r}849 \\
2040 \\
1767 \\
1154\end{array}$ & $\begin{array}{l}24 \cdot 7(21 \cdot 8,27 \cdot 6) \\
23 \cdot 9(22 \cdot 0,25 \cdot 7) \\
20 \cdot 5(18 \cdot 6,22 \cdot 4) \\
21 \cdot 5(19 \cdot 1,23 \cdot 9)\end{array}$ & $\begin{array}{r}794 \\
2645 \\
2068 \\
1062\end{array}$ & $\begin{array}{l}34 \cdot 4(31 \cdot 1,37 \cdot 7) \\
28 \cdot 9(27 \cdot 2,30 \cdot 6) \\
30 \cdot 1(28 \cdot 1,32 \cdot 1) \\
33 \cdot 4(30 \cdot 6,36 \cdot 2)\end{array}$ & $\begin{array}{l}1.58(1.27,1.98) \\
1.31(1.15,1.50) \\
1.74(1.49,2.03) \\
2.03(1.67,2.46)\end{array}$ \\
\hline
\end{tabular}

Table IV General Health Questionnaire (GHQ) mean negative and positive scale scores: comparing respondents from the West London Survey with those from the Health and Lifestyle Survey.

\begin{tabular}{lllll}
\hline & $\begin{array}{l}\text { West London } \\
\text { Survey } \\
\text { (mean }(S D))\end{array}$ & $\begin{array}{l}\text { Health and } \\
\text { Lifestyle Survey } \\
(\text { mean }(S D))\end{array}$ & $\begin{array}{l}\text { Mean }(95 \% \text { CI) } \\
\text { Difference in } \\
\text { scores }\end{array}$ & $\begin{array}{l}\text { Mean }(95 \% \text { CI) } \\
\text { difference after } \\
\text { adjustment }\end{array}$ \\
\hline GHQ negative & $8 \cdot 3(7 \cdot 5)$ & $10 \cdot 6(8 \cdot 1)$ & $2 \cdot 30(2 \cdot 02,2 \cdot 58)$ & $2 \cdot 28(1 \cdot 99,2 \cdot 57)$ \\
GHQ positive & $15 \cdot 0(4 \cdot 0)$ & $15 \cdot 4(5 \cdot 7)$ & $0.41(0.23,0.59)$ & $0 \cdot 41(0 \cdot 22,0.60)$ \\
\hline * Adjusted for age, sex, marital status, employment, social class and housing ownership
\end{tabular}

completed the GHQ in front of the interviewer, while in the Health and Lifestyle Survey, subjects returned the questionnaire to the survey organisation after completing it in their own time. It is very unlikely that these two minor methodological differences could have led to such a large difference in prevalence.

Sixteen per cent of the subjects in the West London survey were asked whether they had a "long standing illness, disability, or infirmity". A comparable percentage of the Greater London respondents of the 1976 General Household Survey reported disability similarly defined. ${ }^{14}$ This suggests that the West London area studied was not atypical of Greater London as a whole. The over 65 year olds in the West London Sample did, however, report less chronic illness than the same age group in the Greater London General Household Survey sample. This may, of course, have resulted from sampling error, rather than reflecting a difference in health status between West London and the whole of Greater London in the elderly. It is therefore possible that the higher prevalence of psychiatric morbidity observed in the over $65 \mathrm{~s}$ (table III) could reflect this aspect of the West London data.

Though it would be ideal to compare surveys conducted in identical areas, these large scale population based surveys using comparable means of assessment are costly and uncommon. If one is to attempt to detect trends in the prevalence of psychiatric disorder in Britain, comparisons can only be done with available information. These surveys, conducted by the same reputable survey organisation (Social and Community Planning Research), were both compared with contemporary census data which indicated close agreement. Evidence is also available to suggest that the West London sample had a similar health status to the whole of Greater London. It is therefore reasonable to conclude that the results of the two surveys can be compared and that it is likely that there was an increase in the prevalence of psychiatric disorder between 1977 and 1985, at least in Greater London.

The GHQ is widely used to assess the prevalence of psychiatric morbidity and has been commonly compared with standardised assessments conducted by psychiatrists. ${ }^{14}$ There is still a possibility, however, that the increase in prevalence observed results from a change in the pattern of response to the GHQ. The results indicate that the increase in prevalence was more noticeable in the portion of the GHQ that assesses negative aspects of mental health. There is some suggestion that the negative part of the GHQ is susceptible to a cultural bias, as Latin American people seem to score more highly on this part of the GHQ (Lewis and Araya, unpublished results). It is therefore possible that the threshold score for defining psychiatric disorder could have increased between 1977 and 1985, though a change of this magnitude seems unlikely.

Little is known of the causes of psychiatric morbidity in the community or why such an increase may have occurred. Though there is evidence that unemployment in men increases the incidence of psychiatric morbidity, ${ }^{26}$ the increase in unemployment between 1977 and 1985 did not account for the increase in psychiatric morbidity 
observed in this study. It is still possible that the fear of unemployment or other factors associated with economic recession could affect mental health. Adverse life events ${ }^{27}$ and poor social support ${ }^{28}$ are also associated with psychiatric morbidity. It is difficult, however, to provide empirical evidence that stressful incidents became more common between 1977 and 1985, or that there is link with the election of a right wing government in Britain in 1979. There has recently been concern that the suicide rate in men aged 15-44 years has been increasing ${ }^{29}$ and the observed increase in the prevalence of psychiatric morbidity may be one possible cause for this.

An increase in the prevalence of psychiatric morbidity of this magnitude has disturbing implications both for public health and the treatment provided by the health service. Though it is difficult now to identify the possible causes of this increase, the finding emphasises the importance that must be attached to determining the causes of psychiatric morbidity in order to inform public health interventions.

We would like to thank Dr Alex Tarnopolsky for help in providing information on the West London Survey.

1 Eagles JM, Hunter D, McCance G. Decline in the diagnosis of schizophrenia among first contacts with psychiatric services in NE Scotland 1969-1984. Br f Psychiatry 1985. 152: $793-798$.

2 Der G, Gupta S, Murray RM. Is schizophrenia disappearing? Lancet 1990, i: 513-16.

3 Croft-Jefferys C, Wilkinson G. Estimated costs of neurotic Croft-Jefferys C, Wilkinson G. Estimated costs of neurotic
disorder in UK general practice 1985. Psychol Med 1989. 19: disorder in

4 Davies LM, Drummond MF. The economic burden of schizophrenia. Psychiatric Bulletin. 1990 14: 522-5.

5 Williams P, Tarnopolsky A, Hand D, Shepherd M. Minor psychiatric morbidity and general practice consultations: the West London Survey. Psychol Med 1986, Suppl 9: Monograph.

6 Klerman G. The current age of youthful melancholia. $\mathrm{Br} 7$ Psichiatry 1988; 152: 4-14.
7 Weissman MM, Bruce ML, Leaf PJ et al. Affective disorders. In: Robins LN, Regier DA eds. Psychiatric disorders in America: the epidemiologic catchment area study New York: Free Press. 1991

8 Goldberg D, Huxley P. Mental illness in the community. London: Tavistock Institute, 1980.

9 Murphy JM. Trends in depression and anxiety: men and Murphy JM. Trends in depression and anxiety:
women. Acta Psychiatr Scand 1986; 73: 113-27.

10 Hagnell O, Lanke J, Rorsman B, et al. Are we entering an age of melancholy? Depressive illness in a prospective epidemiological study over 25 years: the Lundby study, Sweden. Psychol Med 1982; 12: 279-89.

11 Murphy JM, Sobol AM, Neff RK, et al. Stability of prevalence: depression and anxiety disorders. Arch Gen Psychiatry 1984; 41: 990-7.

12 Kessler RC, McRae JA. Trends in sex and psychological distress. Am Sociol Rev 1981; 41: 443-52.

13 Goldberg D. The detection of psychiatric illness by questionnaire. Maudsley Monograph no 21. London: Oxford University Press, 1972.

14 Goldberg D, Williams P. A user's guide to the General Health Questionnaire. Windsor: NFER-NELSON, 1988

15 Tarnopolsky A, Morton-Williams J. Aircraft noise and pischiatric disorders. London: Social and Community and Planning Research, 1980.

16 Cox BD, Blaxter M, Buckle ALJ, et al. The Health and Lifestyle Survev. Cambridge: Health Promotion Research Trust, 1987.

17 Lewis G. Dimensions of neurosis. Psvihol Med 1992; 22 . 1011-18.

18 Rose G. Sick individuals and sick populations. Int $\mathcal{F}$ Epidemiology 1985; 14: 32-8.

19 Rose G, Day S. The population mean predicts the number of deviant individuals. BMF 1990; 301: 1031-4.

20 Statistics and Epidemiology Research Corporation. EGRET I'ersion 0.25.1. Seattle, Washington: Statistics and Epidemiology Research Corporation, 1988.

21 SAS Institute Inc. SAS user's guide: basics, version 5. Cary, NC: SAS Institute Inc, 1985.

22 Lewis G, Booth M. Regional differences in mental health in Great Britain. 7 Epidemiol Community' Health 1992; 46 : 608-11

23 Parker G. Are the lifetime estimates in the ECA study accurate? Psychol Med 1987; 17: 275-82.

24 Williams P, Macdonald A. The effect of non-response bias on the results of two-stage screening surveys of psychiatric on the results of two-stage screening surve

25 Clark VA, Aneshensel CS, Frerichs RR, Morgan TM. Analysis of non-response in a prospective study of Analysis of non-response in a prospective study of depress.

26 Warr P. Work, unemployment and mental health. Oxford: Oxford University Press. 1987.

27 Brown G, Harris T. The social origins of depression. London: Tavistock Institute, 1978

28 Henderson AS, Byrne DG, Duncan-Jones P. Neurosis and the social environment Academic Press: Sydney, 1981

29 Dunnell K. Deaths among 15-44 year olds. Population Trends 1991; 64: 38-43. 